\title{
A DEMOCRATIZAÇÃO DO ENSINO SUPERIOR NO BRASIL, UMA BREVE HISTÓRIA: DA COLÔNIA A REPÚBLICA
}

\author{
THE DEMOCRATIZATION OF HIGHER EDUCATION IN BRAZIL, \\ A BRIEF HISTORY: FROM COLONY TO REPUBLIC
LA DEMOCRATIZACIÓN DE LA ENSEÑANZA SUPERIOR EN BRASIL, UNA BREVE HISTORIA: DE LA COLONIA A LA REPÚBLICA

\section{Sharon Rigazzo Flores i}

\begin{abstract}
RESUMO: O texto apresenta a história da democratização da educação superior no Brasil nos períodos compreendidos entre colônia, império e república. O estudo não teve como objetivo explicar as transformações ocorridas no ensino superior, mas buscou descrever os desafios, problemas e avanços históricos que a população brasileira tem vivenciado para ter acesso a essa modalidade de ensino. O procedimento metodológico utilizado foi a pesquisa bibliográfica. Que como resultado, indica o interesse tardio do governo brasileiro para o estabelecimento de universidades no país, além de mostrar a forte preocupação com o controle e distribuição daquilo que foi intitulado de privilégio aos cidadãos menos abastados. Como consequência é evidenciado o panorama elitista e seletivo das instituições nacionais de ensino superior, tanto quanto uma política hibrida de acesso com investimentos governamentais em instituições públicas, mas também na rede privada de ensino, que nem sempre oferece igual qualidade pedagógica.
\end{abstract}

PALAVRAS-ChAVE: Democratização. Ensino Superior. Brasil. Colônia. Império. República.

ABSTRACT: The text presents the history of the democratization of higher education in Brazil in periods between colony, empire and republic. The study did not aim to explain the transformations that occurred in higher education, but sought to describe the challenges, problems and historical advances that the Brazilian population has experienced in order to have access to this type of education. The methodological procedure used was the bibliographic research. That, as a result, indicates the late interest of the Brazilian government for the establishment of universities in the country, besides showing the strong concern with the control and distribution of what was entitled to privilege to the less wealthy citizens. As a consequence, the elitist and selective panorama of national institutions of higher education, as well as a hybrid policy of access with governmental investments in public institutions, but also in the private education network, which does not always offer the same pedagogical quality, is evidenced.

KEYWORDS: Democratization. Higher education. Brazil. Cologne. Empire. Republic.

RESUMEN: El texto presenta la historia de la democratización de la educación superior en Brasil en los períodos comprendidos entre colonia, imperio y república. El estudio no tuvo como objetivo explicar las transformaciones ocurridas en la enseñanza superior, pero buscó describir los desafíos, problemas y avances históricos que la población brasileña ha vivido para tener acceso a esa modalidad de enseñanza. El procedimiento metodológico utilizado fue la investigación bibliográfica. Que como resultado, indica el interés tardío del gobierno brasileño para el establecimiento de universidades en el país, además de mostrar la fuerte preocupación con el control y distribución de lo que se ha dado el privilegio a los ciudadanos menos favorecido. Como consecuencia se evidencia el panorama elitista y selectivo de las instituciones nacionales de enseñanza superior, tanto como una política hibrida de acceso con inversiones gubernamentales en instituciones públicas, pero también en la red privada de enseñanza, que no siempre ofrece igual calidad pedagógica.

Submetido em: 15/06/2017 - Aceito em: 03/07/2017 - Publicado em: 15/07/2017.

n.2


PALABRAS CLAVE: Democratización. Enseñanza superior. Brasil. Colonia. Imperio. República.

\section{INTRODUÇÃ̃o}

Democratização, substantivo feminino que significa ação ou efeito de democratizar, que por sua vez quer dizer tornar acessível a todas as classes, ou seja, popularizar. Há também quem diga que a democracia é bipolar, aplicada na ironia e mantida em hipocrisia. Então vejamos o que vem acontecendo com a democratização do ensino superior no Brasil, da colônia a república.

\section{O ENSINO SUPERIOR NO BRASIL COLÔNIA (1530-1822)}

Em 1538, a Espanha criou sua primeira universidade no continente americano. A corte portuguesa, por sua vez, não estabeleceu universidade na América até a vinda da família real para o Brasil em 1808, após a invasão das tropas de Napoleão Bonaparte a Portugal.

O que existia até então relacionado ao ensino superior no país eram os cursos de Filosofia, ou também chamado curso de Artes ou Ciências Naturais e o curso de Teologia, ambos mantidos nos colégios da Companhia de Jesus, como o de Todos os Santos, na Bahia, e o de São Sebastião, no Rio de Janeiro.

A principal atividade dos jesuítas se baseava na catequese dos indígenas para torna-los dóceis ao trabalho nas aldeias. Mas também se dedicavam a instrução dos filhos dos colonos onde a educação podia se estender além da escola elementar, o que ocorreu a partir de 1573.

Outras ordens religiosas também mantinham cursos superiores, porém restritos à formação do seu quadro interno, como os franciscanos que no século XVII fundaram um convento de ensino superior voltado para o estudo de teologia e filosofia.

\footnotetext{
Na retaguarda da atividade missionária, os jesuítas mantinham nos centros urbanos mais importantes da faixa litorânea, colégios para o ensino de primeiras letras, para o ensino secundário e superior. Eles se destinavam a cumprir a tripla função: de um lado, formar padres para a atividade missionária; de outro, formar quadros para o aparelho representativo (oficiais de justiça, da Fazenda e da Administração); de outro, ainda, ilustrar as classes dominantes no local, fossem filhos dos proprietários de terra e de minas, fossem os filhos dos mercadores metropolitanos aqui residentes. (CUNHA, 2007, p. 25).
}

O curso de Filosofia/Artes tinha duração de três anos e ao final, o aluno conquistava a formação de bacharel ou licenciado. As disciplinas que compunham o currículo eram: lógica, física, matemática, ética e metafísica. Ao término do curso, o jovem possuía duas opções: estudar teologia ou preparar-se para as profissões liberais. 
O curso de Teologia com duração de quatro anos conferia o grau de doutor, o currículo era composto de duas matérias: teologia moral, relacionada a questões éticas do dia a dia e a teologia especulativa, estudo do dogma católico.

Existia também o curso de letras humanas, que embora a estrutura pedagógica fosse a mesma das universidades europeias, o curso ministrado no Brasil não oferecia o mesmo reconhecimento. Era classificado como de saber desinteressado, pelo fato de não estar vinculado diretamente a uma aplicação prática profissional.

Por esse motivo, os alunos deslocavam-se para uma das diversas faculdades europeias, sobretudo a Universidade de Coimbra. Onde eram submetidos a realizar exames de equivalência caso quisessem prosseguir os estudos nos cursos ditos profissionais, tais como, medicina, direito e engenharia.

Dessa forma, a única maneira dos brasileiros seguir as carreiras liberais, era o estudo na metrópole, mesmo porque, o Colégio da Bahia teve negado o pedido de equiparação à Universidade de Évora, em 1675.

Mais quais eram os jovens que se deslocavam para os estudos na Europa? Os mais abastados, é claro. No entanto, aos poucos, os mulatos começaram a requerer espaço no ensino superior.

Diante da importância dada aos graus acadêmicos para a classificação social, aumentou a procura da escola por parte dos mestiços, o que provocou, em 1689, um incidente conhecido como "questão dos moços pardos": os colégios dos jesuítas haviam proibido a matrícula de mestiços "por serem muitos e provocarem arruaças", (ARANHA, 2006, p. 165).

O padre jesuíta Antônio de Oliveira moveu esforços para o reconhecimento do curso de Filosofia, que só foi conquistado em 1689, antes disso recebeu a seguinte resposta do ministro: "os brancos da Bahia não querem que seus filhos estudem ao lado dos "pardos" que, por essa época estavam impedidos de pertencer a todas as ordens religiosas" (CUNHA, 2007, p. 34). Além disso, em 1681 o mesmo ministro expulsou todos os pardos dos colégios jesuítas.

Esse ponto merece uma pausa. Façamos uma reflexão. $\mathrm{O}$ avanço, quase que inconsciente, no sentido de democratizar o ensino superior, foi boicotado, conscientemente, no momento em que o processo de popularização estava dando os seus primeiros passos. Sendo notório, que antes mesmo do surgimento da universidade como a conhecemos hoje, já existia interesses comprometidos com o projeto elitista e autoritário de sociedade.

Como diria Paulo Freire: "Enquanto violência dos opressores faz dos oprimidos homens proibidos de ser, a resposta destes à violência daqueles se encontra infundida do anseio de 
busca do direito de ser”. (FREIRE, 2014, p. 59).

Os expulsos, então fizeram uma petição ao rei indagando o motivo de serem impedidos de frequentar os colégios no Brasil, mas terem acesso aos colégios jesuítas da metrópole.

Iniciou-se uma disputa entre Estado e a Companhia de Jesus. O Estado dizia que os colégios eram públicos porque sua atividade era subsidiada pelo Estado. Não podiam, portanto, impedirem a admissão de candidatos de qualquer categoria social. A Companhia, por seu lado, dizia que a subvenção do Estado era destinada à conversão dos indígenas, e seus colégios (principalmente os cursos de humanidades e os superiores) eram atividades adicionais, particulares. E, sendo particulares, podiam escolher seus destinatários como lhes aprouvesse. (CUNHA, 2007, p.34).

Além do mais, existiam outros dois aspectos que rodeavam a "questão dos pardos", a quem acreditava que pudessem dar mal exemplo aos brancos, com envolvimento em brigas ou atos de vadiagem, o segundo, mas não menos importante, trazia o argumento do qual considerava que o número de pardos que ingressavam no ensino superior aumentava a cada dia e este fato gerava um certo incomodo para a hegemonia da classe dominante.

Por isso mesmo é que, qualquer que seja a situação em que alguns homens proíbam aos outros que sejam sujeitos da sua busca, se instaura como situação violenta. Não importa os meios usados para esta proibição. Fazê-los objetos é aliená-los de suas decisões, que são transferidas a outro ou a outros. (FREIRE, 2014, p. 104).

Assim, Portugal conduzia uma população pobre e carente de tudo, que vivia à margem de qualquer oportunidade diante da economia agrária e rudimentar, dominada pelo latifúndio e pelo tráfico negreiro, onde a terra era utilizada apenas para dar lucro à metrópole.

Durante o longo período do Brasil Colônia, poucos eram os letrados, a maioria da população era analfabeta, uma vez que a atuação dos jesuítas se fez mais atuante na formação das classes dirigentes, além do trabalho missionário com os indígenas. O que resultou uma elite intelectual formada por bacharéis, burocratas e profissionais liberais.

Sem contar que a metrópole proibia a criação de universidades no Brasil com o propósito de impedir o ensino e a aprendizagem das ciências, das letras e das artes, de modo que mantivesse a ordem existente e evitasse movimentos revolucionários.

Enquanto isso a Espanha, embora também tivesse interesses mercantis em suas colônias, não deixou de organizar nelas cursos superiores em universidades. "Havia na Espanha, no século XVI, oito universidades famosas em toda e Europa, enquanto Portugal dispunha de apenas uma: a de Coimbra, e mais tarde a de Évora, está de pequeno porte", (CUNHA, 2011 P.152153). A variedade de universidades dava aos espanhóis a possibilidade de encaminhar os professores para suas colônias sem prejudicar a dinâmica das aulas na metrópole.

Embora, as universidades surgiram na Europa ainda na Idade Média, o medo de uma rebelião Rev. Inter. Educ. Sup. Campinas, SP $\quad$ v.3 p.401-416 maio/ago. 2017 
tirava o sono da minoria branca. No Brasil, ainda não existia um proletariado urbano. Por isso a pergunta: um sistema escolar para formar quem? Anarquistas? Ninguém precisa saber português ou fazer conta para puxar a enxada, fruto daquela agricultura escravista, cuja concepção era explorar a força de trabalho e não qualificar a mão de obra.

Que tipo de atividade exigia as pessoas lerem no Brasil Colônia? Professor ou cargo público. Os brasileiros não precisavam nem ao menos ler a bíblia. "A educação da imensa maioria dos paulistas das classes populares, praticamente todos analfabetos, resumia-se a uma transmissão essencialmente oral", (MARCILIO, 2005, p.58).

À primeira vista parece até mesmo um contrassenso esse tipo de pensamento. Mas o contrassenso é claro para uma visão que defende a democratização da educação e não na lógica do governo da época, que precisava da máquina funcionando, alguém para operar a máquina do Estado.

"O Brasil enquanto colônia, submetido ao mais estrito monopólio, cresceu isolado do mundo, apenas convivendo 'com aquele pobre e retrógrado Portugal que não permitiu a criação de um sistema popular de ensino no Brasil e, menos ainda, de escolas superiores”. (MARCÍLIO, 2005, p.83).

\footnotetext{
O ensino superior brasileiro como o conhecemos hoje não descendeu, em nenhum aspecto, do enorme edifício que os jesuítas erigiram na colônia. As instituições de ensino superior atualmente existentes resultaram da multiplicação e da diferenciação das instituições criadas no início do século XIX, quando foi atribuído ao Brasil o status de Reino Unido a Portugal e Algarve. Ao fim do período colonial, o ensino superior sofreu, no Brasil, uma tardia refundação. (CUNHA, 2011, p. 153).
}

"Quando chegou na Bahia, Dom João VI, então Príncipe Regente, recebeu a solicitação dos comerciantes locais no sentido de ser criada uma universidade no Brasil; para tanto, dispunham-se a colaborar com uma significativa ajuda financeira”, (OLIVE, 2002, p.32).

Mas ao invés disso, em 1808 o príncipe regente criou estabelecimentos isolados nas regiões norte e sul do país para atender as necessidades do momento. Com isso, foram criados o curso de medicina na Bahia e Rio de Janeiro, que visava à formação de médicos para a marinha e para o exército; Academia Real Militar (1810), para o preparo na carreira militar e formação de engenheiros, além dos Cursos Jurídicos em Olinda e São Paulo (1817).

Os cursos jurídicos traziam uma função de "enobrecimento", eram os mais procurados, sobretudo por que a formação humanística cada vez mais se distanciava do trabalho braçal que por sua vez estava associado ao trabalho escravo. Além disso, o diploma não trazia apenas a incumbência de formar advogados, mas sim magistrados, que conhecedores da lei iriam compor a máquina do Estado. E por esse motivo também atraia a classe média da população em busca de ocupar as funções administrativas. 
Os cursos superiores, mesmo quando transformados em faculdades, permaneceram como institutos isolados, sem que houvesse interesse na formação de universidades (que só foi surgir no século XX). De qualquer forma, a atenção especial dada ao ensino superior reforçava o caráter elitista e aristocrático da educação brasileira, que privilegiava o acesso aos nobres, aos proprietários de terras e a uma camada intermediária, surgida da ampliação dos quadros administrativos e burocráticos. (ARANHA, 2006, p. 226).

"O modelo adotado nessas escolas foi o franco-napoleônico, que se caracterizava por uma organização não universitária, mas profissionalizante, centrado em cursos e faculdades, visando a formação de burocratas para o desempenho das funções do Estado". (PIMENTA, 2010, p.148).

Sem dúvida nenhuma deve-se aos jesuítas a abertura dos primeiros locais de ensino superior no Brasil, bem como a valorização do habito de estudo. A educação jesuítica esteve presente, quase que exclusivamente, nas escolas secundárias, porém isso não impediu que seus métodos fossem utilizados no ensino superior.

\section{O ENSINO SUPERIOR NO IMPÉRIO (1822-1889)}

O ensino superior permaneceu praticamente o mesmo em todo o período imperial. Sendo que, a partir da Lei Geral de 1827, as províncias teriam a responsabilidade pela educação primária, e o poder central o encargo do ensino superior.

Assim, controlado pelo Estado e com uma certa resistência a participação do setor privado, o ensino superior era um mecanismo de monopólio da concessão de privilégios profissionais, que detinha o poder de conferir diplomas juridicamente válidos a uma parcela minoritária da sociedade.

Segundo Cunha (2007), o Estado detinha o monopólio da formação da força de trabalho habilitada para o desempenho de certas profissões, e garantia os interesses de poder, remuneração e prestígio de certos grupos corporativos. Essa era a razão por que o Estado não liberava o ensino superior (capaz de distribuir privilégios) aos particulares.

Gramsci (1980), corrobora com Cunha, quando afirma que: a universidade é a escola da classe (e de pessoal) dirigente. Além disso, amplia a prerrogativa colocada, ao dizer que a universidade também é um mecanismo através do qual se faz a seleção dos indivíduos das outras classes que devem ser incorporados no quadro governante, administrativo e dirigente.

Seguindo um discurso análogo, existiam aqueles, como por exemplo, os liberais, que defendiam a criação de universidades para formar uma elite preparada e competente. 
Mas por outro lado, existiam também os positivistas, que eram contrários a criação da universidade no Brasil, por que defendiam que o recurso seria mais bem empregado se fosse destinado para a instrução popular, ao invés do investimento ser voltado para um pequeno grupo de privilegiados. Embora antagônico quando pensado exclusivamente na democratização do ensino superior, tal discurso é legitimo na visão democrática do ensino dito escalonado. Investe-se prioritariamente na instrução popular, e substancialmente conforme o acompanhamento da demanda criam-se mecanismos para o acesso ao ensino superior.

No entanto, defendida por uns e criticada por outros a universidade não surgiu durante o império. Tanto é que as famílias portuguesas que aqui chegavam comumente seguiam a seguinte tradição: o primeiro filho herdava o engenho do pai, o segundo se dedicava aos estudos das letras e muitas vezes concluíam os estudos na Europa, enquanto o terceiro filho seguia a carreira religiosa.

Até a vinda da corte, o ensino público era estatal e religioso, a Igreja Católica era um setor da burocracia do Estado. Diferente das sociedades protestantes, onde todos precisavam aprender a ler. A ideia de educar a população, não era tida apenas como um valor funcional para a liturgia, mas como um valor em si. Na Inglaterra, isso já era forte no século XVIII, mas não nas sociedades católicas.

No entanto, é inegável que no quesito de manter o país inteiro unido e um sistema representativo funcionando, a máquina do Estado foi extremamente eficiente, em nenhum país da América Latina isso existia. Então desse ponto de vista os portugueses lograram muito êxito.

Assim, mesmo após a expulsão dos jesuítas, os estabelecimentos de ensino superior no período pombalino continuaram sendo dirigidos por religiosos e com forte conteúdo religioso.

Embora ao longo do Império vários projetos de formação de universidades tiveram suas respostas sempre recusadas, foi ao final deste período que ocorreu o aumento do interesse pela educação, com a criação de bibliotecas, museus, além de ampliação dos debates através de conferências que traziam como tema a preocupação com a educação do país.

\section{O ENSINO SUPERIOR NA REPÚBLICA}

Somente após a proclamação da república, em 1889 que a igreja permaneceu exclusivamente no âmbito da sociedade civil. Nesse período o ensino se desdobrou em duas ramificações: estatal laico, particular religioso ou particular laico.

Aqueles que se posicionavam contra o ensino superior particular, argumentavam a falta de Rev. Inter. Educ. Sup. Campinas, SP $\quad$ v.3 p.401-416 maio/ago. 2017 
interesse da iniciativa privada, enquanto que outros diziam que tal situação acarretaria na perda da qualidade do serviço prestado para a população. Além do mais, como já mencionado anteriormente, o ensino particular gerava uma ameaça ao monopólio do Estado na concessão de privilégios profissionais.

O aumento do número de diplomados poderia produzir, pela diminuição da raridade, a perda do valor intrínseco do diploma, em termos de poder, prestígio e remuneração, para os grupos corporativos compostos por indivíduos oriundos das classes dominantes ou cooptados por elas e interligados a níveis mais elevados da burocracia do Estado. (CUNHA, 2007, p. 86).

Mesmo diante desses dilemas, as primeiras décadas da República foram marcadas pela expansão do ensino superior, ocasionada pela multiplicação das faculdades. Nesse período sugiram as primeiras universidades no Brasil. No Rio de Janeiro em 1920 e em Minas Gerais em 1927, e mudanças no processo de admissão ${ }^{2}$. Que passaram a ser parcelados, realizado por matéria, no tempo e lugar mais conveniente para os candidatos e com prazo de validade permanente.

Além disso, pelo decreto 981, de 08 de novembro de 1890 elaborado por Benjamin Constant, o exame de madureza de saída do ensino secundário passou a ser exame de entrada para o ensino superior.

Mas ao mesmo tempo que aumentava o acesso, cresciam as resistências a esse processo. Os opositores da expansão do ensino superior queixavam-se da invasão dessa modalidade por candidatos inabilitados, acrescentavam que a falta de preparo dos estudantes do ensino secundário prejudicava o desempenho dos alunos no ensino superior.

Com isso, em 1911 foi promulgado por decreto a Lei Orgânica do Ensino Superior, redigida pelo ministro do Interior, o deputado Rivadávia da Cunha Corrêa, que instituía o exame de admissão para o ingresso nas escolas superiores, cujo objetivo era identificar a capacidade intelectual dos candidatos para realizarem com êxito o estudo das matérias que constituíam o ensino da faculdade.

A normatização do exame se deu com a promulgação dos decretos 8.661 e 8.662 , ambos de 5 de abril de 1911. De acordo com esses decretos, os candidatos deveriam apresentar, no ato da matrícula, os seguintes documentos: certidão de idade, provando ter, no mínimo, 16 anos; atestado de idoneidade moral; certificado de aprovação no exame de admissão; e, recibo da taxa de matrícula.

\footnotetext{
${ }^{2}$ A admissão dos candidatos às escolas superiores estava condicionada, desde 1808, à aprovação nos chamados exames preparatórios, prestados no estabelecimento de ensino procurado. Mais tarde, a partir de 1837, os concluintes do curso secundário do recém-criado Colégio Pedro II passaram a ter o privilégio de matrícula, sem exames, em qualquer escola do Império. (CUNHA, 2007, p.154).

\begin{tabular}{|l|l|l|l|l|l|} 
Rev. Inter. Educ. Sup. & Campinas, SP & v.3 & n.2 & p.401-416 & maio/ago. 2017
\end{tabular}
}


Em 18 de março de 1915, foi promulgado o decreto 11.530, pelo então ministro da Justiça e do Interior Carlos Maximiliano Pereira dos Santos, que reorganizava o ensino superior rebatizando os exames de admissão para exames vestibulares, além disso, para que o candidato fosse admitido também era necessário apresentar um certificado de aprovação das matérias do curso ginasial, realizado no Colégio Pedro II ou nos colégios estaduais a ele equiparados e fiscalizados pelo Conselho Superior de Ensino. Tal exigência ajudou a reduzir bastante o ingresso de alunos no ensino superior.

O caráter seletivo/discriminatório dos exames vestibulares sofreu aperfeiçoamento. Pelo regime de 1915, não havia limites numéricos para admissão numa faculdade qualquer. Todos os estudantes que fossem aprovados tinham direito a matrícula. A reforma de 1925 estabelecia o dever do diretor de cada faculdade na fixação do número de vagas, a cada ano. Em consequência, os estudantes aprovados eram matriculados por ordem de classificação, até estarem completadas as vagas. (CUNHA, 2007, p. 171).

Isto posto, em 13 de janeiro de 1925 por meio do decreto 16.782-A, que ficou conhecido pelo nome do professor da Faculdade de Medicina do Rio de Janeiro, Juvenil da Rocha Vaz, foi concretizado o processo de des-democratização do ensino superior brasileiro. Que além de dificultar o acesso, também institui as seguintes contas a pagar para os alunos matriculados nos estabelecimentos federais: taxa de exame vestibular, taxa de matrícula e de frequência por série, taxa de frequência de cadeira, taxa de exame e taxa de transferência.

Todavia, tal decreto não passou imune a críticas. Durante esse período surgiu o primeiro movimento de empoderamento estudantil, a União Nacional dos Estudantes (UNE), que defendia a universidade aberta a todos; a diminuição das taxas de exame e matrícula; liberdade de pensamento; a dependência da universidade diante do Estado; a elaboração do currículo por professores especializados e representantes dos estudantes; e o aproveitamento de alunos como monitores e estagiários.

A maioria desses estudantes eram oriundos das camadas médias, filhos de funcionários do Estado e de empresas particulares, assim como de profissionais liberais. Isso porque a década de 30 foi marcado pela consolidação da sociedade urbano industrial brasileira e pela criação de novos empregos urbanos, tanto no setor público como no privado.

Além do mais, entre 1920 e 1930, o ensino superior foi alvo de muitas críticas, principalmente por estar mais voltado ao ensino do que à pesquisa, conservando a orientação profissional dos seus cursos, principalmente quando comparado com as atividades vigentes em outros países.

De acordo com (NAGLE, 1974), a sobreposição do ensino em detrimento a pesquisa, pode ser explicado pela ausência de escolas superiores voltadas para a cultura desinteressada, de base, destinadas à especialização intelectual, como filosofia, ciência ou literatura, e isso,

n.2

p.401-416

maio/ago. 2017 
dificultava a organização da escola superior em outros moldes, como o do regime universitário, tão aclamado desde os fins do império.

No ano de 1926 o jornal O Estado de S. Paulo, publicou uma série de reportagens de autoria do jornalista Fernando de Azevedo, posteriormente designado para assumir o Departamento de Instrução Pública do Distrito Federal. As reportagens destacavam, entre outros, que o ensino superior era instituído preferencialmente por escolas profissionais, inexistindo instituições dedicadas ao saber livre e desinteressado de aplicação imediata. Além disso, denunciava a insuficiência das escolas profissionais de medicina, direito e engenharia.

Para Fernando de Azevedo, que também foi um dos principais colaboradores do Manifesto dos Pioneiros da Educação $\mathrm{Nova}^{3}$, não havia contradição entre a formação de elites, na forma proposta, e a democracia. Isso porque para Azevedo, no regime democrático as elites são abertas, formadas por cooptação. Ou seja, a educação proporciona a cada indivíduo a descoberta de vocações e conhecimento de capacidades. Assim, a elite se renova e se recruta em todas as camadas sociais.

Entretanto, esse não era o pensamento do governo militar, que considerava a universidade pública como centro de subversão e ameaça aos objetivos de segurança e desenvolvimento. Por outro lado, viam com bons olhos a expansão do setor privado, embora fossem dependentes da ajuda financeira do Estado, mas que segundo a sua ótica, as faculdades isoladas dificultavam a mobilização política dos estudantes.

Essas faculdades não eram locais de atividades de pesquisa, dedicavam-se exclusivamente ao ensino. Mas também atendiam a uma demanda cada vez maior pelo aumento do número de vagas, tanto na periferia das grandes metrópoles e cidades de médio porte, como no interior dos estados mais desenvolvidos, passando a atuar também nos centros urbanos.

A partir da década de 1930, no governo provisório de Getúlio Vargas, o então ministro da educação e saúde Francisco Campos efetivou através de decreto as seguintes reformas que visavam à organização nacional da educação, tais como: regime universitário, criação do Conselho Nacional da Educação, do ensino secundário e do comercial, além da organização das Universidades.

De acordo com Fávero (2000), para o Ministro, a universidade tinha duplo objetivo: "equiparar tecnicamente as elites profissionais do País e proporcionar ambiente propício às vocações especulativas e desinteressadas, cujo destino, imprescindível à formação da cultura nacional, é o da investigação e da ciência pura”. (CAMPOS, 1931, p.4).

\footnotetext{
${ }^{3}$ Em suma, no que diz respeito ao ensino superior, o Manifesto dos Pioneiros da Educação apresentava duas vertentes, uma delas o papel das universidades em formar as elites dirigentes e a outra o seu papel de difundir ideais políticos próprios para a construção da democracia.

\begin{tabular}{l|l|l|} 
Rev. Inter. Educ. Sup. & Campinas, SP & v.3
\end{tabular}

\begin{tabular}{l|l} 
n.2 & p. $401-416$
\end{tabular}

maio/ago. 2017
} 
Neste período, embora algumas Universidades já existissem, resultavam da simples agregação de faculdades. Era o caso da Universidade do Rio de Janeiro (1920) e da Universidade Federal de Minas Gerais (1927). Seguido pela Universidade de São Paulo (USP) em 1934. Também é importante mencionar a Universidade do Brasil, criada em 1937 como um modelo para as demais universidades do país, e que em 1965 deu origem a Universidade Federal do Rio de Janeiro (UFRJ).

Aqui cabe destacar o importante papel desempenhado pelo professor Fernando Magalhães, considerado o primeiro reitor da Universidade do Rio de Janeiro, ao defender o papel democrático da universidade, quando afirma que: "para efeitos da cultura, base essencial da nacionalidade, a universidade será muito mais popular do que doutoral, constituindo-se não só empório de diplomas, mas um distribuidor de conhecimento. Cabe-lhe, além e acima disso, educar o povo ${ }^{4}$.

No entanto, foi em 1968 através da Lei $\mathrm{n}^{\circ}$ 5.540/68, que ocorreram profundas transformações no ensino superior, de acordo com Aranha:

\begin{abstract}
A reforma extinguiu a cátedra (cargo de professor universitário, titular em determinada disciplina), unificou o vestibular e aglutinou as faculdades em universidades para e melhor concentração de recursos materiais e humanos, tendo em vista a maior eficácia e produtividade. Instituiu também o curso básico nas faculdades para suprir as deficiências do $2^{\circ}$ grau e, no ciclo profissional, estabeleceu cursos de curta duração e longa duração. Desenvolveu ainda um programa de pósgraduação. (ARANHA, 2006, p.317).
\end{abstract}

Foi também durante o final da década de 60 e início da década de 70 que deu início a um grande processo de privatização do ensino superior. Conforme os dados apresentados na tabela a seguir:

Tabela 1. Evolução das matrículas da educação superior brasileira por

\begin{tabular}{cccccc}
\multicolumn{2}{c}{ categoria } & \multicolumn{3}{c}{ administrativa (pública e privada) $-1994-2004$} & \\
\hline \multirow{2}{*}{ Ano } & Total & Matrículas públicas & \multicolumn{2}{c}{ Matrículas privadas } \\
& & Total & $\%$ & Total & $\%$ \\
\hline 1964 & 142.386 & 87.665 & 61,6 & 54.721 & 38,4 \\
1974 & 937.593 & 341.028 & 36,4 & 596.565 & 63,5 \\
1984 & 1.399 .539 & 571.879 & 40,9 & 827.660 & 59,1 \\
\hline
\end{tabular}

\footnotetext{
${ }^{4}$ URJ. Revista da Universidade do Rio de Janeiro, série II, no 1, p.12, 1932.
} 


\begin{tabular}{llllll}
\hline 1994 & 1.661 .034 & 690.450 & 41,6 & 970.584 & 58,4 \\
2004 & 4.163 .733 & 1.178 .328 & 28,3 & 2.985 .405 & 71,7 \\
\hline
\end{tabular}

Fonte: BRASIL.MEC/INEP. Sinopse da Educação Superior, 2017.

De acordo com a tabela 1, o número de matrículas entre 1964-2004 passou de 142.386 para 4.163.733, ou seja, aumentou em mais de vinte e nove vezes. A primeira vista, o crescente número de matrículas pode parecer uma grande oportunidade para tornar acessível a todas as classes, ou seja, popularizar o ensino superior, mas a concentração das matrículas na rede privada em detrimento da rede pública, nem sempre oferecia igual qualidade pedagógica.

Para os cursos superiores de baixo nível dirigiam-se os jovens menos abastados, porque, mal preparados para a disputa pelas vagas, não tinham acesso às melhores faculdades, geralmente as públicas, cuja demanda por matrículas era muito maior que a oferta de vagas, e por esta razão tais instituições, implantavam mecanismos bastante seletivo.

Isto posto, começam a surgir programas do governo federal com duas vertentes, uma voltada para os alunos que estavam matriculados nas instituições privadas e a outra para os alunos matriculados nas instituições públicas.

O primeiro programa de crédito educativo, no Brasil, criado em 1976 concedia para estudantes da rede privada o financiamento das mensalidades, e para os estudantes da rede pública, a sua manutenção durante o ensino superior. $\mathrm{O}$ prazo de pagamento do aluno era equivalente ao tempo de duração do curso.

Assim foi sendo constituída a democratização do ensino público brasileiro, de 1974 a 1984, aqueles que podiam pagar por um ensino particular estudavam em instituições públicas, enquanto que aqueles que mal podiam dar conta de sua sobrevivência, quando do acesso ao ensino superior, o fazia majoritariamente em instituições privadas. Pois ao que tinha, mais lhe era dado, mas, ao que quase não tinha, até o pouco lhe era tirado.

Em 1999 para impedir o desmoronamento do programa, ou seja, a crescente taxa de inadimplentes, o crédito educativo foi remodelado dando origem ao FIES - Fundo de Financiamento ao Estudante do Ensino Superior, que neste momento passou a atender exclusivamente os alunos dos cursos superiores não gratuitos e com avaliação positiva, o que de certa forma fez com que as faculdades cuja receita dependessem do crédito educativo, realizassem ajustes para melhorar a qualidade do ensino ofertado. Além disso, em 2010 aumentou o prazo do aluno para o pagamento em até três vezes o tempo do curso.

A opção do país pela variedade das instituições de ensino superior (pública e privada), onde a maior parta da receita das faculdades particulares dependiam do crédito educativo, continuou 
em 2002 com a inauguração do plano de governo para a educação, intitulado: Uma escola do tamanho do Brasil, que para fomentar a ampliação do acesso ao ensino superior trazia como proposta a expansão de vagas, em especial com a revisão e ampliação do crédito educativo e a criação de programa de bolsas universitárias, com recursos não-vinculados constitucionalmente à educação, além da ampliação de investimentos no setor público e em cursos noturnos.

Dentro dessa linha de raciocínio (público e privada), em 2005 através da Lei nº 11.096, o governo instituiu o Programa Universidade para Todos (PROUNI), que passou a oferecer bolsas de estudo integrais e parciais (50\%) em cursos de graduação. Assim como, por outro lado em 2007 criou o Programa de Apoio a Planos de Reestruturação e Expansão das Universidades Federais - REUNI, instituído pelo Decreto n ${ }^{\circ}$ 6.096, de 24 de abril de 2007, além da ampliação dos Institutos Federais de Educação, Ciência e Tecnologia (IFs).

No entanto, embora o viés para a democratização do ensino superior tinha um caráter hibrido, com os recursos sendo repartidos entre a iniciativa privada e as instituições públicas. De acordo com a tabela 1, é fácil observar que o maior número de matrículas a partir da década de 70 se deslocou para as instituições particulares.

Mas é possível reconhecer também o esforço do governo federal para permitir o acesso dos estudantes em instituições públicas de ensino, mas é claro, sem deixar de lado o financiamento dos estudantes nas instituições privadas. Assim em 2010 foi implantado o Sistema de Seleção Unificada (SISU), onde através do Exame Nacional do Ensino Médio (Enem), os estudantes conseguem participar do processo seletivo nas instituições públicas de educação superior localizadas em todo o território nacional, além de permitir o acesso a programas governamentais de financiamento estudantil.

Em 2012 avançando ainda mais no processo de democratização é instituída a Lei ${ }^{\circ}$ 12.711, popularmente conhecida como Lei de Cotas, que garantiu a reserva de $50 \%$ das matrículas por curso e turno nas 59 universidades federais e 38 institutos federais de educação, ciência e tecnologia a alunos provenientes integralmente do ensino médio público com renda familiar bruta igual ou inferior a um salário mínimo e meio per capita e metade para estudantes de escolas públicas com renda familiar superior a um salário mínimo e meio.

Além disso, dentre todas as vagas reservada a cotistas, também foi levado em conta o percentual mínimo correspondente ao da soma de pretos, pardos e indígenas por estado, de acordo com o último censo demográfico do Instituto Brasileiro de Geografia e Estatística (IBGE), assim, conseguiu-se garantir um número proporcional de matriculas para esses alunos de acordo com à participação dessa população em cada estado. 


\section{CONSIDERAÇõES FINAIS}

As instituições de ensino superior no Brasil ao longo da história foram organizadas para atender aos interesses do seu tempo, o que não necessariamente significava a democratização do ensino superior.

Durante a colônia, o modus operandi no país era a colonização de exploração. Por esta razão, não existia a preocupação com a instrução acadêmica da população, formada principalmente por escravos e indígenas e uma economia rural. Ainda não existia no Brasil um proletariado urbano. $\mathrm{O}$ analfabetismo era geral. A concepção do governo baseava-se em explorar a força de trabalho e não qualificar a mão de obra.

Ao final do período colonial e início do império, a vinda da família real e o incremento das atividades mercantis aumentaram a demanda pela formação universitária, no entanto, este período foi marcado por uma trajetória de caráter elitista, voltada para a formação da elite dirigente e pouco flexível para o recrutamento de indivíduos menos favorecidos.

Posteriormente cogitou-se a participação da iniciativa privada, mas a falta de interesse das instituições particulares, o receio da ameaça ao monopólio do Estado, somado a preocupação sobre a perda de qualidade do serviço prestado impediram o avanço da ideia.

Ao pensar sobre o ensino superior basta uma visão local, como por exemplo, o questionamento numa sala de aula sobre a formações dos familiares dos alunos para perceber que ainda é um nível de ensino pouco frequentado no Brasil, quem dirá então um século atrás.

Durante a república, com a consolidação do proletariado urbano a procura pelo ensino superior aumentou. Contudo, surgiram questionamentos sobre a falta de preparo dos estudantes. $\mathrm{O}$ que resultou na criação dos exames de admissão, posteriormente denominados vestibulares, com o objetivo de identificar a capacidade intelectual dos candidatos e selecionar os melhores para o preenchimento das vagas nas universidades públicas.

Em seguida, os mecanismos de acesso são repensados. As matrículas que antes estavam concentradas no Estado passam a ser ofertadas também pelas instituições particulares.

Os incentivos então oscilam, ora aumentando o apoio para as instituições particulares através do financiamento estudantil, o FIES e o fomento para bolsas de estudos pelo PROUNI.

Ora aumentando o número de vagas nas universidades públicas ou melhorando a logística de ingresso com a visão territorial de acesso as vagas através do ENEM ou até mesmo com a Lei de Cotas, com o aumento do alcance social e racial.

Assim, durante a república, milhões de brasileiros conseguiram acesso à universidade, e com Rev. Inter. Educ. Sup. \begin{tabular}{l|l} 
Campinas, SP & v.3
\end{tabular} p.401-416 maio/ago. 2017 
isso um caminho para ascensão social. Os números de faculdades multiplicaram pelo país, mas quem alimentou essa expansão foram as universidades particulares, que hoje são responsáveis por $70 \%$ das matrículas.

Em 2004 o ministério da educação reforçou o controle de qualidade com a criação do Exame Nacional de Desempenho dos Estudantes (ENADE). Os resultados foram longe dos ideais. As faculdades particulares apresentaram as piores notas, enquanto as públicas as melhores.

Portanto, se não existir uma educação de qualidade, jamais teremos uma real democratização do ensino superior, mas apenas um símbolo de status, de emprego, de uma vida melhor, que não passará de uma farsa aplicada na ironia e mantida em hipocrisia.

\section{REFERÊNCIAS}

ABRUCIO, Fernando Luiz. A dinâmica federativa da educação brasileira: diagnósticos e propostas de aperfeiçoamento. In: Oliveira, Romualdo Portela, Santana, Wagner. (Org.). Educação e federalismo no Brasil: combater as desigualdades, garantir a diversidade. Brasília: UNESCO, 2010.

ARANHA, Maria Lúcia de Arruda. História da Educação e da Pedagogia: geral e Brasil. 3 ed. rev. e ampl. São Paulo: Moderna, 2006.

CAMPOS, Francisco. Exposição dos motivos apresentados ao Exmo. Sr. Chefe do Governo Provisório, em 2 de abril de 1931. In: BRASIL. Ministério da Educação e Saúde Pública. Organização Universitária Brasileira. Decretos n¹9.850, 19.851 e 19.852 de 11 de abril de 1931. Rio de Janeiro: Imprensa Nacional, 1931.

CUNHA, Luiz Antonio. Ensino Superior e Universidade no Brasil. In: Lopes, Eliane Marta Teixeira. Faria, Luciano Mendes. Veiga, Cynthia Greive. (Org.). 500 Anos de Educação no Brasil. 5ºd., Belo Horizonte: Autêntica, 2011.

CUNHA, Luiz Antonio. A universidade temporã: o ensino superior, da Colônia à Era Vargas. 3. ed., São Paulo: Editora Unesp, 2007.

FÁVERO, Maria de Lourdes de A. Universidade do Brasil: das origens à construção. Rio de Janeiro: Editora UFRJ/Inep, 2000.

FREIRE, Paulo. Pedagogia do Oprimido. 58 ed.rev. e atual. Rio de Janeiro: Paz e Terra, 2014.

GRAMSCI, Antonio. Maquiavel, a política e o Estado Moderno. Rio de Janeiro: Civilização Brasileira, 1980. 
MARCILIO, Maria Luiza. História da escola em São Paulo e no Brasil. São Paulo:Instituto Braudel - Imprensa Oficial, 2005.

NAGLE, Jorge. Educação e sociedade na Primeira República. São Paulo: EPU, 1974.

OLIVEN, Arasela Campos. História da educação superior no Brasil. In: Soares, Maria Susana Arrosa (Org.). A Educação Superior. Brasília: Coordenação de Aperfeiçoamento de Pessoal de Nível Superior, 2002.

PIMENTA, Selma Garrido. ANASTASIOU, Lea das Graças Camargos. A Universidade no Brasil: breve gênese. In: Pimenta, Selma Garrido. Docência no Ensino Superior. 4.ed., São Paulo: Cortez, 2010. (Coleção Docência em Formação).

\section{${ }^{\mathrm{i}}$ Sobre a autora \\ Sharon Rigazzo Flores}

E-mail: sharon.rigazzo@ifsp.edu.br / ORCID: http://orcid.org/0000-0003-0890-6096

Universidade Estadual Paulista - Brasil

Mestrado pela Universidade Federal de São Carlos [UFSCar]. 